\title{
Mars: South Polar Pits and Etched Terrain ${ }^{1}$
}

\author{
Robert P. Sharp \\ Division of Geological and Planetary Sciences, California Institute of Technology \\ Pasadena, California 91109
}

\begin{abstract}
Sharply delineated closed depressions, one-half to tens of kilometers across, with 400 meters estimated maximum depth, are locally abundant in the south polar region. They indent the surface of a massive homogeneous blanket that mantles the cratered bedrock surface. Some pits extend through the blanket exposing the underlying rock floor, and, where the blanket is thin (50-100 meters), its extensive removal exposes large ares of exhumed rock floor producing a terrain described as etched. The blanketing material is speculatively interpreted to be an eolian sedimentary deposit containing a mixture of fine particulate matter, possibly including volcanic ash, and particles of frozen volatiles, principally $\mathrm{CO}_{2}$ and $\mathrm{H}_{2} \mathrm{O}$. Fields of dunes, groups of linear grooves and flutes, and an unusual scoured topography on the surface of layered blanketing material suggest strong wind action. For this reason, deflation by wind, aided by ablation (evaporation) of included frozen volatiles, is regarded as the most likely mechanism for producing the south polar pits and etched terrain. Pitted and etched terrains and the deposits into which they are cut suggest that the south polar region, and presumably the north polar area as well, have experienced alternating episodes of eolian deposition and erosion.
\end{abstract}

In its 1969 flight past Mars, Mariner 7 photographed some highly irregular closed depressions near the prime meridian at latitudes of $70^{\circ}-74^{\circ} \mathrm{S}$, within the area then covered by annual polar frost [Sharp et al., 1971]. These were unlike any features seen on Mariner 6 and 7 pictures at lower latitudes. They were termed etch pits from a resemblance to forms etched by a corroding agent, but in 1969 it was uncertain whether these pits existed solely within the annual frost cover or were features of the underlying substrate.

The Mariner 9 pictures of 1971-1972 clearly establish that the pits are features of the substrate. They are further shown to be extremely abundant in some areas poleward of $73^{\circ} \mathrm{S}$ (Figures 1 and 2) and to occur in a wide variety of shapes, sizes, and arrangements (Figure 3 ).

The simple term pit is now used for these topographically closed depressions, and areas extensively indented by such features are termed pitted terrain. As pits enlarge, they become integrated, eventually producing a terrain de-

\footnotetext{
${ }^{1}$ Contribution 2266, Division of Geological and Planetary Sciences, California Institute of Technology, Pasadena, California.
}

Copyright (c) 1973 by the American Geophysical Union. scribed as etched. Etched terrain is seen within the south polar region at about $70^{\circ} \mathrm{S}$ (Figure 1).

Although pitted and etched terrains are unusual and interesting in themselves, their principal value lies in the information they provide concerning the history and the evolution of the south polar area and of Mars. Particularly significant is the indication of alternating episodes of deposition and erosion within the south polar region. Considerations are limited to the region poleward of $65^{\circ} \mathrm{S}$, although pictures from the north polar area also suggest the existence of pitted terrain there [Soderblom et al., 1973a].

\section{South Polar Sedimentary Blankets}

The Mariner 7 flight of 1969 revealed that much of the region southward of $80^{\circ} \mathrm{S}$ latitude was craterless and relatively smooth. This has been confirmed by Mariner 9 pictures, which also show large areas of smooth terrain (at resolutions of 1-2 km) extending north to at least $70^{\circ} \mathrm{S}$ latitude. About $60 \%$ of the region poleward of that latitude has very low relief. These featureless areas are now seen to be covered by mantles of material that bury the cratered bedrock surface [Murray et al., 1972].

It is not a function of this article to provide a thorough description of these blankets; they are being treated in detail by Cutts [1973b]. 


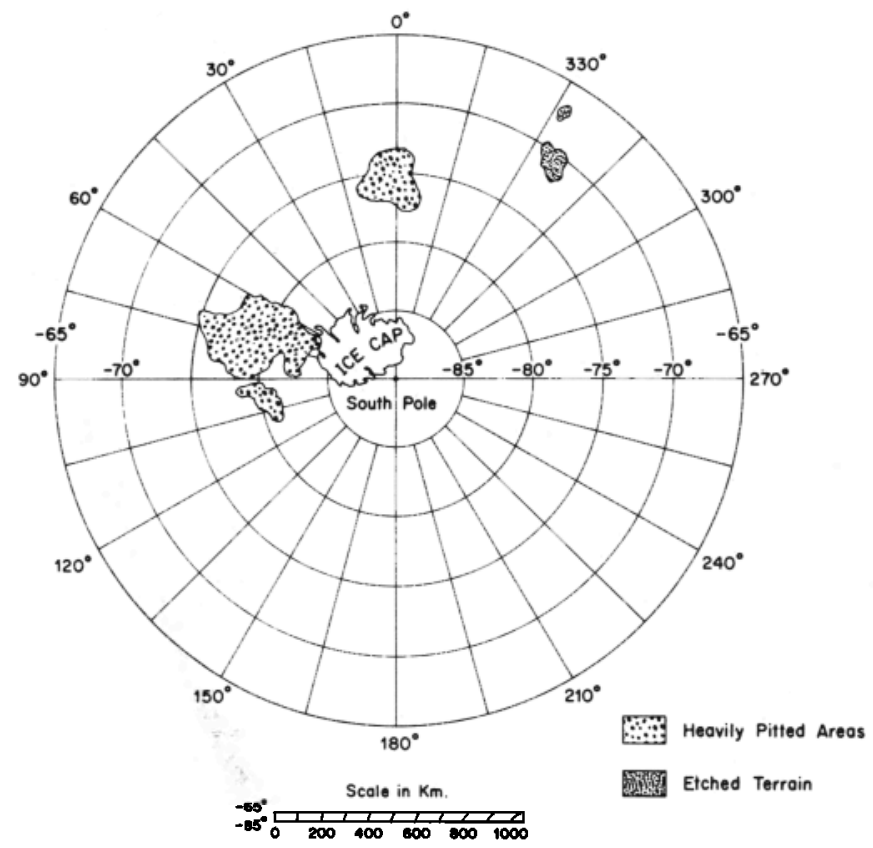

Fig. 1. Map of south polar area showing location of the principal areas of pitted and etched terrain.

However, they are so intimately associated with pitting and etching that some knowledge of their salient characteristics is needed. The types of blankets identified are shown in Table 1. The residual ice sheet and the annual frost cover are more ephemeral phenomena not treated here.

Part of the area covered by the layered blanket is a smooth nearly featureless plain bearing the imprint of shallow linear grooves and a few small fresh bowl-shaped craters. Elsewhere, this blanket has been extensively eroded, exposing a well-developed internal layering (Figure $3 b$ ), which appears to be essentially horizontal. As many as $\mathbf{5 0}$ individual beds can be identified in single exposures. The

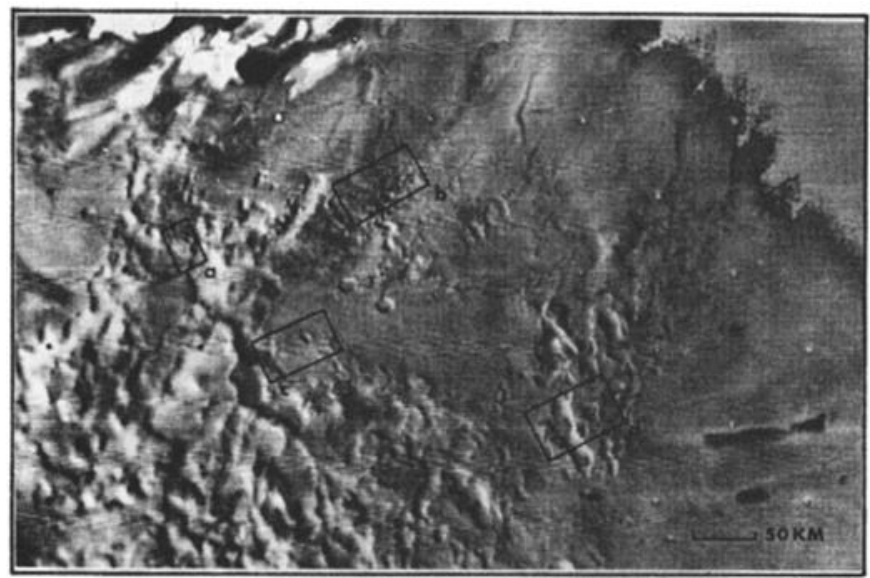

Fig. 2. Pitted terrain peripheral to south polar residual ice sheet, upper left. (MTVS 4251-20, DAS 09375004.) Details of pitting and related features are shown in closeup views in Figure 3. 


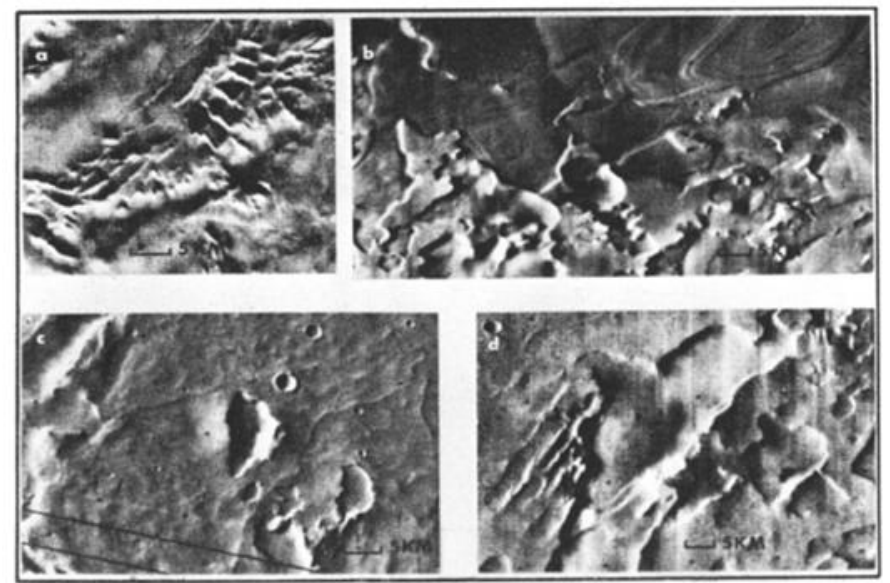

Fig. 3. Details of areas of pitted terrain outlined in Figure 2. (a) Structures in massive blanket etched out by wind to produce a quasi 'Inca City.' (MTVS 4261-12, DAS 09734769.) (b) Irregular pits in massive blanket and a remnant of the younger layered blanket. (MTVS 4247-7, DAS 09231189.) (c) Pits in massive blanket with unusual abundance of young craters. (MTVS 4251-24, DAS 09375039.) (d) Pit complex in massive blanket. (MTVS 4146-3, DAS 05918715.)

total thickness of the layered blanket is estimated, with considerable uncertainty, at 0.5 to possibly several kilometers [Cutts, $1973 b$; Murray et al., 1973; Soderblom et al., 1973a; C. Sagan, 1973].

The layered blanket appears to rest unconformably on one or more massive blankets and in some places directly on the uneven bedrock surface. This stratigraphic relationship and the paucity of craters on its surface suggest that the layered sequence is the youngest of all the polar blankets, except the annual frost and the residual ice sheet. Although extensively eroded and locally pocked with smooth-sided shallow hollows, the stratified blanket does not display pitting and etching of the type to be described.

Remnants of massive unlayered blankets also mantle parts of the south polar region. The youngest of these, seemingly homogeneous and structureless, is the most extensively pitted and etched unit (Figures 2, 3, 4, and 5). Its thickness is conservatively estimated to range from about 400 meters at $80^{\circ}-70^{\circ} \mathrm{S}$ to about 50 meters at $65^{\circ} \mathrm{S}$.

This structureless unit appears to rest unconformably on one or more still older massive blankets, which locally, at least, have strongly developed near-vertical linear to gently curving structures. These structures locally consist of intersecting sets, which have been etched out by differential erosion to produce regular geo- metrical patterns, the most striking of which was christened 'Inca City' (Figure $3 a$ ).

Constitution of both the layered and the massive blankets is strictly a matter of speculation. One of the more appealing suggestions is that they are eolian accumulations consisting of fine particulate matter, some possibly of volcanic origin, that fell from the atmosphere along with, or alternating with, particles of frozen volatiles, largely $\mathrm{H}_{2} \mathrm{O}$ and $\mathrm{CO}_{2}$ [Murray et al., 1972; Cutts, 1973a, b; Murray et al., 1973].

\section{PITS}

Geometry and size. Pits of the south polar region are sharply outlined closed depressions with abrupt walls (Figure 4). They range primarily from one-half to several tens of kilometers across and have a maximum depth of at least $\mathbf{4 0 0}$ meters, conservatively calculated from an assumed $10^{\circ}$ wall slope. Large pits are deeper than small pits, and some compound

TABLE 1. Types of Martian South Polar Blankets

$\begin{array}{ll}\text { Youngest } & \text { 1. } \begin{array}{c}\text { Layered blanket (unpitted but } \\ \text { highly sculptured) }\end{array} \\ \text { 0ldest } & \text { 2. Massive blankets } \\ & \text { (a) Homogeneous and structure- } \\ & \text { 1ess (most extensively pitted } \\ \text { and etched) } \\ \text { (b) Locally prominently struc- } \\ \text { tured (strongly eroded) }\end{array}$



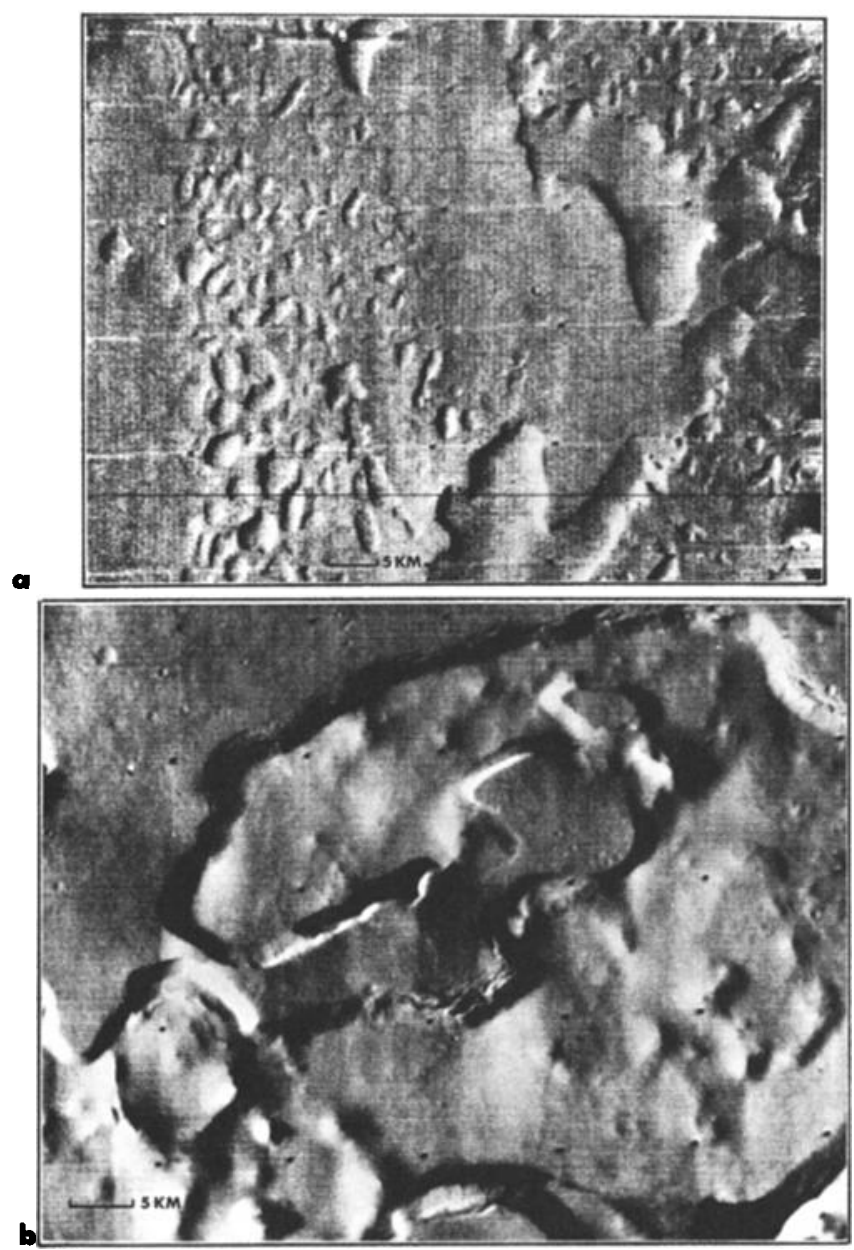

Fig. 4. (a) Assemblage of pits within massive sedimentary blanket at $73.7^{\circ} \mathrm{S}, 66.8^{\circ} \mathrm{W}$. (MTVS 4132-21, DAS 05453843.) (b) A large complex pit at $71.1^{\circ} \mathrm{S}, 358.3^{\circ} \mathrm{W}$, which exposes rough bedrock floor underlying massive blanket. Steep slump-marked walls and local dark albedo markings on floor merit note. (MTVS 4234-15, DAS 08763869.)

pits, formed by integration, have stepped floor levels. Outlines range from simple and smoothly curving to cuspate, irregularly indented, and locally angular where structural control is strong. Pits occur in groups, and the term pitted terrain is applied to areas where pits are especially numerous (Figure $4 a$ ). In some places the shapes and patterns of pits seemingly reflect control by structures in the pitted blanket or the influence of some directional property of the eroding agent. However, a lack of consistency in shape and arrangement is common elsewhere.

Pit floors. Some floors are smooth, and others are rough. Aside from local strong al- bedo markings, smooth floors display only gentle undulations or minor topographic irregularities at the foot of pit walls and a very few small (0.5-1 km) fresh bowl-shaped craters.

Rough floors have knobs, ridges, and craters of two varieties: small fresh bowl-shaped craters and larger (to $10 \mathrm{~km}$ ), deteriorated craters, many of which retain remnants of what looks like a central filling. It will be argued later that these rough floors have been exhumed from beneath the blanketing material. Smooth-floored pits, by contrast, have bottomed within the blanket.

Pit walls. Pit walls break sharply from the surrounding upland, and most wall faces appear 
smooth at the limit of resolution (0.3-0.4 km). Only faint suggestions of orthogonal scarrings are seen on some, and a few show small scallops just below the brink. Occasional slump blocks and slump cracks are associated with pits (Figure $4 b$ ). In profile the walls appear largely straight with a steepening just below the brink and a concave transition at the base. Their slope is not known, but for depth calculation it is conservatively estimated at $10^{\circ}$. With one possible exception, layering has not been seen in the wall materials. Outliers of the dissected blanket composing small buttes and mesas have bounding slopes with features like those of pit walls.

The extramarginal upland. The upland surface immediately bordering pits is mostly smooth and relatively featureless. It is but sparsely indented, to different degrees in different areas, by fresh bowl-shaped relatively small $(<10 \mathrm{~km})$ craters. The upland surface is also scarred by parallel grooves up to $0.5 \mathrm{~km}$ wide and several kilometers long, and it locally bears groups of irregular wavelike ridges. Additionally, upland surfaces display parallel flutes, circular depressions $(0.5 \mathrm{~km}$ across $)$, and short irregular ridges in various configurations that produce a finely textured appearance.

\section{Etched TerRain}

Near its thin outer edge, removal of the blanketing sheet is so extensive that the terrain can no longer be characterized as pitted. It is better termed etched (Figure 5). Etched ter-

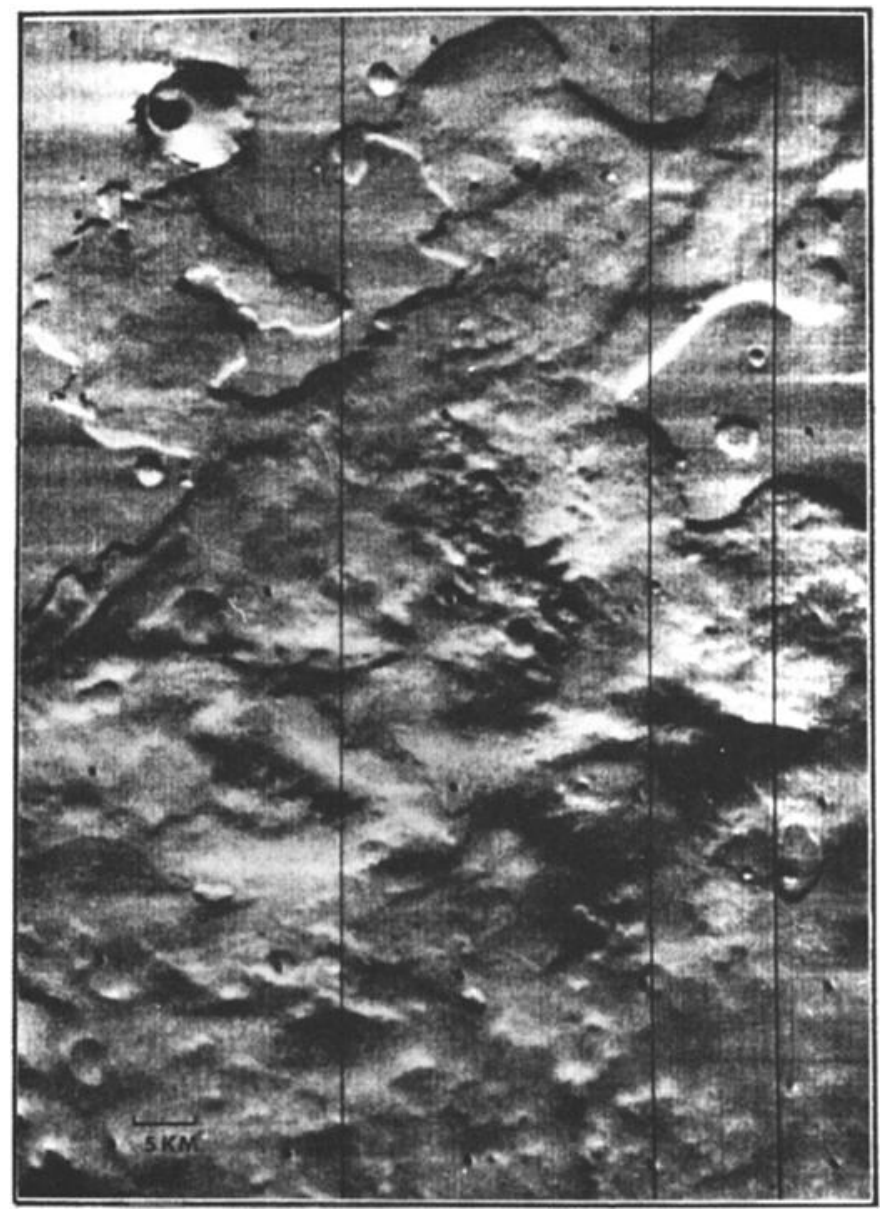

Fig. 5. Representative etched terrain at $67.1^{\circ} \mathrm{S}, 326.1^{\circ} \mathrm{W}$. The ragged edge of the thin massive blanket, the rough exhumed bedrock floor, the outlier of the blanket, and the small fresh craters all are notable. (MTVS 4200-105, DAS 07648203.) 
rains develop where the massive blanketing material has an estimated thickness of only 50-100 meters. Since thinning occurs northward, the best etched terrain area is in the neighborhood of $70^{\circ} \mathrm{S}$ (Figure 1). In addition to the highly irregular planimetric arrangements of blanket remnants (Figure 5), the other striking characteristic of etched terrain is the exhumed bedrock floor.

\section{Evidences of Wind Action IN South Polar Area}

With pits and etched terrain put aside momentarily, attention is directed to other features on the south polar blankets that can reasonably be attributed to the work of wind. Several groups of transverse wavelike ridges are seen in narrow angle pictures. In the best of these (Figure $6 a$ ) the ridges display shapes and patterns like those of transverse dunes on the earth, although the $0.5-$ to $1-\mathrm{km}$ spacing of ridge crests is large by terrestrial standards. However, the resolution is about $0.5 \mathrm{~km}$, and so smaller features possibly present are simply not visible. A significant number of small irregular clusters of little mounds and ridges observed in the south polar area may also be dunes, an interpretation suggested by their setting within the
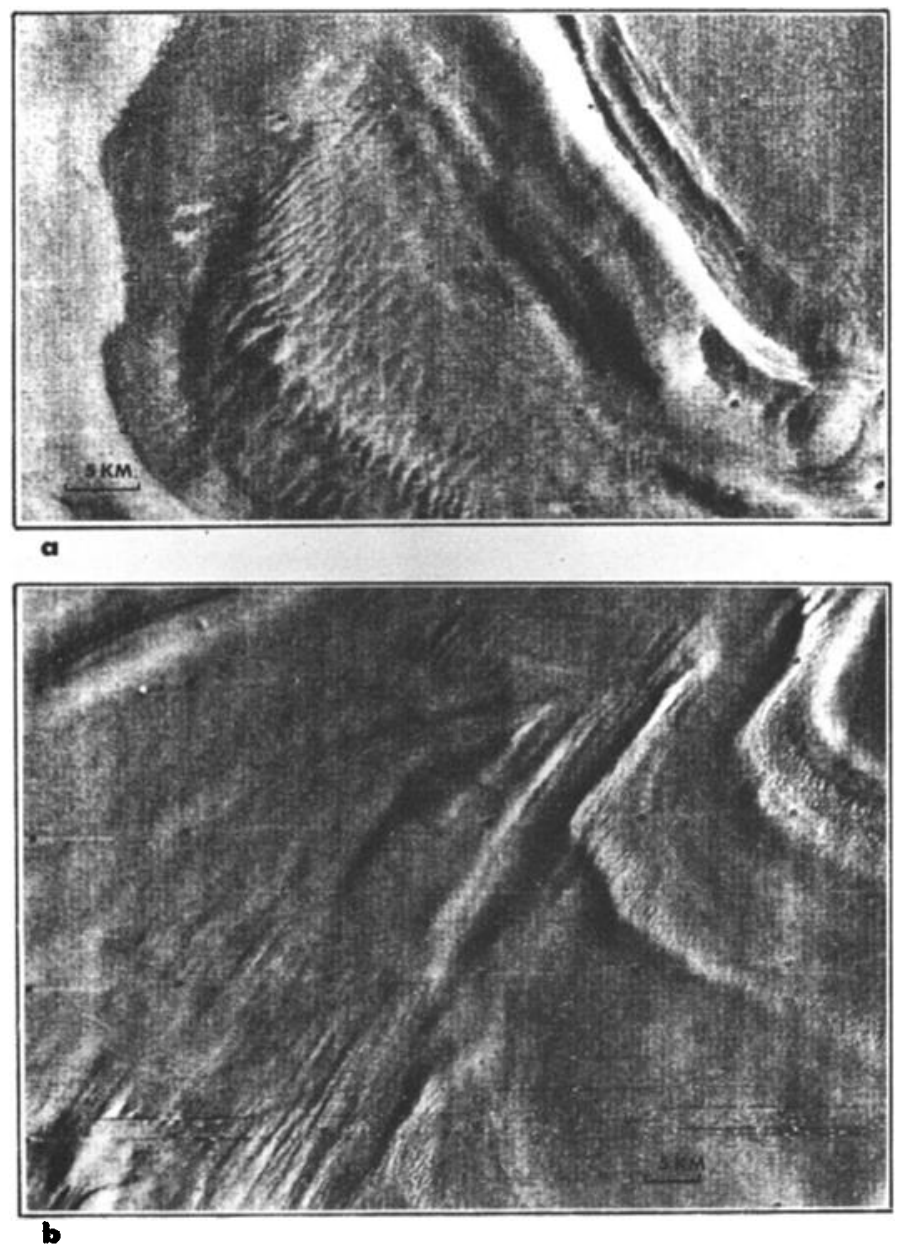

Fig. 6. (a) Cluster of transverse dunes in a broad hollow on surface of layered blanket at 81.9 ${ }^{\circ}$, 48.7 ${ }^{\circ}$ W. (MTVS 4286-104, DAS 10684504.) (b) Linear grooves and flutes attributed to wind cutting on surface of layered blanket at $86.7^{\circ} \mathrm{S}, 270^{\circ} \mathrm{W}$. (MTVS $4248-12$, DAS 09267099.) 
surrounding terrain. On the earth, dunes are composed of sand, not of finer materials such as dust or clay, unless the latter are pelletized [Blackwelder, 1934, 1946]. It seems a reasonable assumption that dunes in the Martian south polar area are also composed of sand-sized particles.

Erosional features of possible eolian origin are currently more evident and more widely displayed than depositional forms on the south polar blankets. The topographic surface of the layered blanket has clearly been produced by some erosional process, for the surface truncates the depositional layers. Although the topography reflects some control by the layering, it has an unusual overall appearance, lacking the integration and organization of normally dissected landscapes. The gracefully curving slopes, the streamlined hills and ridges, and the curiously shaped hollows and niches suggest that it was formed by a medium that flowed as a mass across the entire surface. Because the area is peripheral to the residual south polar ice cap, the possibility of glacial erosion has been entertained. Ice is a surprisingly facile agent of erosion; however, at the temperatures now prevailing in the south polar region, the amount of slip occurring at the base of an ice sheet, and therefore the amount of basal erosion, would be nil. The ice would be firmly frozen to the substrate, unless one postulates a layer of liquid carbon dioxide as Sagan [1973] has done.

The other agent likely to produce morphology of this type is wind, and the topographic surface looks more characteristic of wind scouring than ice scouring, especially in terms of hollows, niches, and reentrants. The probability of wind scour is supported by the abundant quasiparallel grooves, somewhat resembling large yardangs [Blackwelder, 1934], which curve, fan out, or converge in delicate adjustment to larger topographic forms. Even more suggestive of wind action are the short stubby flutes that mark the surface in some areas. Plots of groove and flute orientation [Cutts, 1973a] suggest that the wind blew outward from the south pole in a clockwise spiral.

In summary, the features and relationships just described suggest that winds have strongly scoured the surface of the presumably fine- grained sedimentary blankets of the south polar region, a conclusion also reached by Cutts [1973a].

\section{ExhUMation}

The case for exhumation is based principally on geometrical patterns and the unusual appearance of knobs, ridges, and craters on exhumed bedrock surfaces as compared with their appearance elsewhere on Mars. The following points are noted. (1) The complex planimetric pattern involving blanketed spots and intervening bedrock lowland areas would be difficult or impossible to create by any depositional mode. It is easily formed by selective erosion. (2) The highly irregular frayed margin of the blanket and the outliers of blanket material forming small buttes and mesas suggest erosional removal. (3) Windows within the remnant blanket, which expose the underlying rough floor, have the configuration of erosional rather than depositional features. (4) The interior depression of many craters on the bedrock floor appears to be largely filled, creating what might be called a crater ring. (5) Bedrock knobs and ridges rising above the lowland have a peculiar appearance, possibly resulting from a residual mantling of their flanks. (6) In some instances one part of a crater is almost wholly obscured by blanketing material, but the other part is clearly exposed. It is easier to produce this relationship by erosion than by deposition if the blanketing material has been laid down from a suspended state in the atmosphere. (7) The number and size of fresh bowl-shaped craters indenting the surface of the massive blanket remnants, although small, are significantly greater than on the rough lowland floor. Although the lowland surface is older in absolute terms, as is shown by its population of larger degraded craters, it has been exposed to recent cratering for a shorter time. While the blanket was accumulating fresh craters, the underlying floor was still buried and protected.

Exhumation is probably not limited to the south polar region, because other areas on Mars also show the peculiar appearance of an exhumed topography [Soderblom et al., 1973b]. However, exhumation is seemingly widespread in the south polar region and constitutes a significant chapter in its history. 


\section{Origin of Pits and Etched Terrain}

Closed depressions can be created by localized removal of material upward, downward, or laterally. The fact that the bedrock surface, on which the surficial blankets of the south polar region rest, appears intact in pit floors indicates that localized downward movement of material as a mass has not occurred. The configuration and arrangement of the pits further indicate that lateral spreading is an unlikely cause. This leaves upward movement as the most likely possibility and explosion or deflation as the most probable mechanisms.

Explosions, whether of volcanic or impact origin, create predominantly circular depressions surrounded by a rim of ejected debris, neither of which characterizes the south polar pits. Thus, by elimination, deflation appears to be the most feasible mechanism, and this possibility is supported by the evidence for extensive wind erosion just recounted. If the polar region blankets contain frozen volatiles, evaporation could also contribute significantly to pit formation, and the genetic process would then involve a combination of deflation and ablation. Restriction of pits to the south polar blankets, which may be wholly of eolian origin [Cutts, $1973 a, b]$, favors wind work. What the atmosphere brings, the atmosphere can presumably take away. A blanket of eolian origin will necessarily be composed of well-sorted uniformly fine-grained debris, which means that armoring of the surface by concentrations of coarse immobile deflation-inhibiting particles would not develop. The presence of dunes in the polar area, presumably composed of mobile sand-sized particles, is further supportive of the eolian hypothesis. Few things are more effective than saltating sand grains for blasting finer particles into the air so that they can be carried away in suspension.

The modest depth, an estimated $50-400$ meters, of polar pits is also a favorable factor. Although 400 meters exceed the depth of hollows on the earth attributed to deflation [Ball, 1927, 1933; Berkey and Morris, 1927; Smith, 1969], it is not inconsistent with the estimated strength [McCauley, 1973], duration, and virtually unopposed action of winds on Mars. Deflation on the earth is almost always opposed by other processes tending to fill hollows created by wind.

Walls of Martian polar depressions are sharp brinked and more abrupt than the walls of most terrestrial deflation hollows of large size. Slumps and orthogonal scars on some Martian pit walls suggest the possibility of wall recession caused by an undermining process. In this regard, frozen volatiles could be important, especially if they happen to be concentrated or enriched within specific zones or layers. Their evaporation could produce an undermining that would keep the walls steep and cause them to recede.

Etched terrain is regarded simply as an advanced stage of pit development that occurs primarily where the mantling blanket is thin $(50-100 \mathrm{~m})$. Expanded pits have coalesced producing large bedrock areas denuded of the overlying mantle.

For these various reasons and considerations the pits and etched terrain of the south polar region are attributed to a combination of deflation and ablation.

\section{Discussion}

The south polar pits and etched terrain have interesting implications as to the history of the polar region and of the planet. They attest to alternating episodes of eolian deposition and erosion. Sometimes the south polar area has served as a sump for the accumulation of airborne debris and associated particles of frozen volatiles. At other times the wind patterns or wind effectiveness change, and the atmosphere begins to remove the blanket of material it has earlier spread over the south polar region.

Causes for the alternating episodes of erosion and deposition are speculative. They could be related to astrophysical variations involving precession of the planetary axis and other orbital perturbations [Murray et al., 1973], or possibly to episodes of volcanism, of which there is ample independent evidence, that periodically filled the atmosphere with volatiles and fine volcanic dust, some of which ended up in the polar sumps because of considerations previously outlined by Leighton and Murray [1966]. During periods of volcanic quiescence the prevailing polar winds could have partly removed the accumulated materials by deflation and ablation. 
The surficial appearance of south polar blankets indicates that the present, or the immediate past, has been a period primarily of removal. Relationships between individual blankets further suggest that erosional removal has not always been completed before further accumulation occurred. The alternation between deposition and erosion has happened more than once, and possibly more often than the visible evidence indicates. The freshness, paucity, and small size of craters on the current surfaces of blanket remnants indicates that those surfaces are not particularly old in terms of Martian history. and that different blankets are clearly of different ages. The fact that any craters are seen at all indicates some antiquity in view of the rather strong flux of erosional and depositional activity. The older blanket remnants may date back tens to hundreds of millions of years.

An additional indication of at least modest antiquity for older massive blanket remnants is their internal structure of seemingly nearvertical fractures. Processes localized by these structures could have hardened adjacent materials, which were then etched into positive relief by subsequent erosion (Figure 3a). Volcanic fluids or gases moving surfaceward along fractures could result in such an alteration, a possibility that merits consideration because of the independent evidence of polar region volcanism provided by features interpreted as cones, craters, and lava flows. However, the respective temporal relationship of local volcanism and blanket accumulation is not known.

A record of accumulation and erosion is preserved in the south polar region and in the north polar area as well [Soderblom et al., 1973a]. These episodes must reflect changes that also affected nonpolar areas of Mars, and such relationships are described by Soderblom et al. [1973b].

Acknowledgment. So many people have played a part in contributing to the success of the Mariner 9 photographic mission that to enumerate any by name does disservice to others unmentioned. Those people who have had a role in this great scientific adventure will know it and hopefully will take satisfaction from the publication of the results.

\section{ReFerences}

Ball, J., Problems of the Libyan Desert, Geogr. $J ., 70,21,1927$.

Ball, J., The Qattara Depression of the Libyan Desert and the possibility of its utilization for power production, Geogr. J., 88, 289, 1933.

Berkey, C. P., and F. K. Morris, Geology of Mongolia, Natural History of Asia, vol. 2, $475 \mathrm{pp}$., American Museum of Natural History, Washington, D.C., 1927.

Blackwelder, E., Yardangs, Geol. Soc. Amer. Bull., $46,159,1934$.

Blackwelder, E., Evolution of desert playgs, Geol. Soc. Amer. Bull., 57, 1179, 1946.

Cutts, J. A., Wind erosion in the Martian polar regions, J. Geophys. Res., 78, this issue, $1973 a$.

Cutts, J. A., Nature and origin of layered deposits of the Martian polar regions, J. Geophys. Res., 78, this issue, 19736 .

Leighton, R. B., and B. C. Murray, Behavior of carbon dioxide and other volatiles on Mars, Science, 169, 133, 1966.

McCauley, J. F., Mariner 9 evidence for wind erosion in equatorial and mid-latitude regions of Mars, J. Geophys. Res., this issue, 1973.

Murray, B. C., L. A. Soderblom, J. A. Cutts, R. P. Sharp, D. J. Milton, and R. B. Leighton, Geological framework of the south polar region of Mars, Icarus, 17, 328, 1972.

Murray, B. C., W. R. Ward, and S. C. Yeung, Periodic insolation variations on Mars, Science, 180, 638, 1973.

Sagan, Carl, Liquid carbon dioxide and the Martian polar laminas, J. Geophys. Res., 78, this issue, 1973.

Sharp, R. P., B. C. Murray, R. B. Leighton, L. A. Soderblom, and J. A. Cutts, The surface of Mars, 4, South polar cap, J. Geophys. Res., 76, 357, 1971.

Smith, H. T. U., Photo-interpretation studies of desert basins in northern Africa, Rep. 68-0690, Air Force Cambridge Res. Lab., Bedford, Mass., 1969.

Soderblom, L. A., M. C. Malin, J. A. Cutts, and B. C. Murray, Mariner 9 observations of the surface of Mars in the north polar region, $J$. Geophys. Res., 78, this issue, $1973 a$.

Soderblom, L. A., T. J. Kreidler, and H. Masursky, Latitudinal distribution of erosional debris on the Martian surface, J. Geophys. Res., 78, this issue, $1973 b$.

(Received January 24, 1973; revised March 14, 1973.) 